\title{
ENERGY HOMEOSTASIS OF THE ARTIFICIAL BLADDER IN EXPERIMENTAL CONDITIONS
}

\author{
Ruslan Savchuk \\ Department of Urology and Nephrology \\ Odessa National Medical University \\ 2 Valikhovskyi lane, Odessa, Ukraine, 65082 \\ Savrus7@rambler.ru \\ Fydor Kostyev \\ Department of Urology and Nephrology \\ Odessa National Medical University \\ 2 Valikhovskyi lane, Odessa, Ukraine, 65082 \\ rudenko_v_@mail.ru \\ Yriy Dekhtiar \\ Department of Urology and Nephrology \\ Odessa National Medical University \\ 2 Valikhovskyi lane, Odessa, Ukraine, 65082 \\ ddoctor@i.ua \\ Dmitriy Zhukovskij \\ Department of Urology and Nephrology \\ Odessa National Medical University \\ 2 Valikhovskyi lane, Odessa, Ukraine, 65082 \\ dazhukovskij@gmail.com
}

\begin{abstract}
Patients with malignant neoplasms of the bladder or severe anatomical and functional bladder abnormalities are the candidates for cystectomy and orthotopic urine diversion. The distal portion of the ileum is the most frequent anatomical organ, which is used for the formation of the urinary conduit. The formation of a urinary reservoir from the ileum that is unable to perform new functions, and mainly programmed to isolate enzymes, digest food and absorb nutrients, salts and minerals changes the energy exchange in the ileum wall under the influence of urine.

The aim of the research is the examination of energy metabolism changes in the ileum wall during the formation of artificial bladder in experimental conditions conducted on mini-pigs. Experimental studies were performed on 21 female mini-pigs with an average age of 6 to 14 months. The duration of the experiment was 12 months. An imbalance of the ATP-ADP-AMP system was observed in the transplant tissue of the graft in different postoperative periods. Changes in the level of ATP are characteristics of the development of tissue ischemia.

Results. The values of the adenosine nucleotides sum (the energy potential indicative of the respiration rate of mitochondria) and the phosphorylation index were lower at different times of observation in the transplant tissue. The energy charge value was lower to a lesser extent relative to the control.

Conclusion. The revealed changes in the level of adenosine nucleotides confirm the severity of the disturbances of the energy homeostasis in the transplant tissue at all stages of the observation.

Keywords: cancer bladder, cystectomy, ileocystoplasty, artificial bladder, energy homeostasis, energy potential, adenosine monophosphate, adenosine diphosphate, adenosine triphosphate, ileum.

(C) Ruslan Savchuk, Fydor Kostyev, Yriy Dekhtiar, Dmitriy Zhukovskij
\end{abstract}

\section{Introduction}

Patients with malignant neoplasms of the bladder or severe anatomical and functional abnormalities of the bladder may be candidates for cystectomy and orthotopic urine diversion $[1,2]$. The aim of the reconstructive operation is to create a urinary reservoir, which is functionally ca- 
pable of adapting to the bladder in periods of urine accumulation and emptying, and maintaining renal function $[3,4]$.

The most frequent anatomical organ used for the formation of the urinary conduit is the distal portion of the ileum [5,6]. The intestine transplant has the properties of resorption of urine components with the development of hyperchloremic acidosis, possibly urodynamic disorders of the upper urinary tract and the progression of renal failure, which complicates the course of the long-term postoperative period in the initially severe and age-related contingent of patients [7, 8]. Metabolic acidosis develops in $15 \%$ of patients with a formed conduit, in $50 \%$ of patients with intestinal reservoir from the ileum, and in $80-100 \%$ of patients with a reservoir of the large intestine [9].

The formation of a urinary reservoir from the ileac part, which is unable to perform new functions, and also programmed to isolate enzymes, digest and absorb nutrients, salts and minerals, may also change the energy exchange in the ileum wall during contact with urine. The metabolic processes in the wall of the neobladder have not been sufficiently studied during a certain period under the influence of new conditions of functioning [10, 11].

The adenylate system is an important component of energy-producing and energy-transport cell systems. The adenosine nucleotides are capable to modify cellular functions and affect the contractile activity of smooth muscle through participation in purinergic receptors $[12,13]$.

Thus, it can be assumed that the role in the development of overactivity and hypoactivity of the neocyst was due to the modification of the properties of enterocytes, which, in response to mechanical and chemical stimuli, are able to change their properties, like nerve cells.

\section{Aim of research}

The aim of investigation is the examination of energy metabolism changes in the ileum wall during the formation of artificial bladder in experimental conditions conducted on mini-pigs.

\section{Materials and methods}

Studies were conducted in 2017 in the department of biochemistry SI «Filatov Institute of Eye Diseases and Tissue Therapy of NAMS of Ukraine».

Scientists have proved that the organism of pigs in its anatomical and morphofunctional features is the closest to humans and ideal for studying the pathogenesis of various morphological and biochemical processes [14].

Experimental studies were performed on 21 female mini-pigs, at an average age of 6 to 14 months. The duration of the experiment was 12 months. The experimental model of the artificial bladder was reproduced by performing cystectomy in animals with ileocystoplasty in anesthesia. The biopsies were taken from the neocyst followed by biochemical studies of the macroergs at 3, 6 and 12 months after the ileocystoplasty.

The tissue samples were homogenized with $3 \mathrm{ml}$ of $6 \%$ perchloric acid in the intestinal tissue and then the neocyst of mini-pigs in a ratio of 1:7 (weight:volume) to determine the content of ATP, ADP and AMP. The resulting acidic tissue homogenate was centrifuged at $5{ }^{\circ} \mathrm{C} 10 \mathrm{~min}$ at $10.000 \mathrm{rpm}$. The resulting deproteinized supernatant was neutralized with a $1.75 \mathrm{M}$ solution of trisubstituted potassium phosphate $(\mathrm{pH}$ 7.0-7.5). The solution stirred and cooled for 15 minutes. The neutral extract was centrifuged at $3.000 \mathrm{rpm}$ for 10 minutes. A neutral supernatant was used for the assay [15].

The parameters characterizing the state of the energy exchange under the experimental conditions were calculated on the basis of the obtained data, which are:

- energy charge (EC) by the formula

$$
\mathrm{EC}=(\mathrm{ATP}+1 / 2 \mathrm{ADP}) /(\mathrm{ATP}+\mathrm{ADP}+\mathrm{AMP})
$$

- energy potential (EP) by the ratio

$$
\mathrm{EP}=\mathrm{ATP} / \mathrm{ADP}
$$


- thermodynamic control of respiration (TCD) by the ratio

$$
\mathrm{TCD}=\mathrm{ADP} / \mathrm{AMP}
$$

- index of phosphorylation (IP) by the formula:

$$
\mathrm{IP}=\mathrm{ATP} /(\mathrm{ADP}+\mathrm{AMP})[16]
$$

The animals were taken out of the experiment by decapitation during anesthesia, adhering to the provisions of the "European Convention for the Protection of Vertebrates used for experiments or for other scientific purposes".

The reliability of the discrepancy $(\mathrm{P})$ between the values was determined by the Student's $\mathrm{t}$ test. Differences were considered statistically significant at $\mathrm{p}<0.05$.

\section{Results}

The violations of energy exchange in varying degrees of severity were detected in the transplant tissue from the intestine, depending on the observation period.

The level of ATP, ADP and AMP in the tissues of the intestine (control) and "intestinal" transplant (neocyst) was examined at 3,6 and 12 months after surgery (Table 1). It was observed given that adenosine nucleotides, especially ATP, occupy an important place in the energy metabolism, and ADP stimulates the respiratory chain in the tissue cells and, along with AMP, are positive allosteric regulators of enzymatic processes.

Table 1

\begin{tabular}{|c|c|c|c|c|c|}
\hline Indicator & Functional role & $\begin{array}{l}\text { Statistical } \\
\text { indicator }\end{array}$ & $\begin{array}{c}3 \text { months } \\
(n=21)\end{array}$ & $\begin{array}{c}6 \text { months } \\
(n=19)\end{array}$ & $\begin{array}{c}12 \text { months } \\
(n=19)\end{array}$ \\
\hline \multirow{8}{*}{ ATP } & \multirow{4}{*}{ Intestine (control) } & M & 1.64 & 1.59 & 1.60 \\
\hline & & $\mathrm{m}$ & 0.12 & 0.13 & 0.11 \\
\hline & & $\mathrm{p}$ & - & - & - \\
\hline & & $\%$ & 100.0 & 100.0 & 100.0 \\
\hline & \multirow{4}{*}{ Neobladder } & M & 0.95 & 1.03 & 1.08 \\
\hline & & $\mathrm{m}$ & 0.06 & 0.07 & 0.06 \\
\hline & & $\mathrm{p}$ & $<0.001$ & $<0.01$ & $<0.001$ \\
\hline & & $\%$ & 57.9 & 64.8 & 67.5 \\
\hline
\end{tabular}

Content of ATP in ileum mini-pigs and neocyst after transplantation (nmol/g)

Note: $p$ - the level of significance of data differences according to intestinal tissue

A decrease of ATP levels were observed in the tissue of the formal bladder compared to the intestinal wall after 3 months by $42.1 \%(\mathrm{p} \leq 0.001)$, in 6 months by $35.2 \%(\mathrm{p} \leq 0.001)$ and after 12 months by $32.5 \%(\mathrm{p} \leq 0.001)$, which testifies to the suppression of the energy homeostasis in neocyst. The progressive increase in the level of ATP was observed in the examined transplant after 12 months from the beginning of the experiment, which may indicate activation of the adaptation process in the neobladder. There was also a progressive increase in the level of ATP in the examined transplant after 12 months from the beginning of the experiment, which may indicate activation of the adaptation process of the neobladder.

Table 2 presents the content of ADP and AMP in ileum and neocyst, where is also noted the suppression of the energy producing function, according to control, but without statistically significant positive dynamics during the 12 months of the experiment. The prolonged suppression of energy homeostasis is possibly due to the toxic effect of urine on enterocytes, the difference in the programmed vital activity of cells in the intestine and vital activity in new conditions. 
Table 2

The content of ADP and AMP in ileum mini-pigs and neocyst after transplantation (nmol/g)

\begin{tabular}{|c|c|c|c|c|c|}
\hline Indicator & Functional role & $\begin{array}{l}\text { Statistical } \\
\text { indicator }\end{array}$ & $\begin{array}{c}3 \text { months } \\
(n=21)\end{array}$ & $\begin{array}{c}6 \text { months } \\
(n=19)\end{array}$ & $\begin{array}{c}12 \text { months } \\
(n=19)\end{array}$ \\
\hline \multirow{8}{*}{ ADP } & \multirow{5}{*}{ Intestine (control) } & M & 0.53 & 0.54 & 0.52 \\
\hline & & $\mathrm{m}$ & 0.03 & 0.04 & 0.03 \\
\hline & & $\mathrm{p}$ & - & - & - \\
\hline & & $\%$ & 100.0 & 100.0 & 100.0 \\
\hline & & M & 0.40 & 0.43 & 0.41 \\
\hline & \multirow{3}{*}{ Neobladder } & $\mathrm{m}$ & 0.02 & 0.02 & 0.03 \\
\hline & & $\mathrm{p}$ & $<0.01$ & $<0.05$ & $<0.05$ \\
\hline & & $\%$ & 75.5 & 79.6 & 78.8 \\
\hline \multirow{8}{*}{ AMP } & \multirow{5}{*}{ Intestine (control) } & M & 0.27 & 0.32 & 0.25 \\
\hline & & $\mathrm{m}$ & 0.02 & 0.02 & 0.02 \\
\hline & & $\mathrm{p}$ & - & - & - \\
\hline & & $\%$ & 100.0 & 100.0 & 100.0 \\
\hline & & M & 0.21 & 0.25 & 0.20 \\
\hline & \multirow{3}{*}{ Neobladder } & $\mathrm{m}$ & 0.01 & 0.02 & 0.01 \\
\hline & & $\mathrm{p}$ & $<0.05$ & $<0.05$ & $<0.05$ \\
\hline & & $\%$ & 77.8 & 78.1 & 80.0 \\
\hline
\end{tabular}

Note: $p$ - the level of significance of data differences according to intestinal tissue

The sum of nucleotides in the ileum homogenate and neobladder in Fig. 1, is shown, as a decrease in energy production observed at $36.07 \%(\mathrm{p} \leq 0.001)$ after 3 month, which indicates a depression of mitochondrial respiration. Subsequent studies at 6 and 12 months did not demonstrate statistically significant changes in the sum of nucleotides compared to the primary study 3 months after the start of the experiment.

Sum of nucleotides in ileum and neobladder

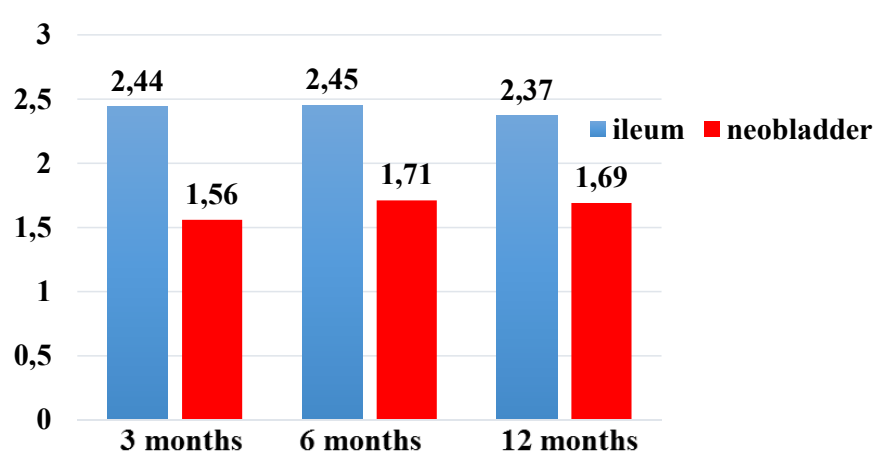

Fig. 1. The sum of nucleotides in ileum and neobladder $(p \leq 0.001)$

The Fig. 2 shows the energy charge (EC) in the ileal tissue of experimental animals and neocyst during the experimental study at 3,6 and 12 months. Energy charge is an indicator characterizing the fullness of the ATP, ADP, and AMP system with macroergic phosphate bonds. This system is considered to be filled, when its value approaches one. In such state, all adenosine phosphates are in the form of ATP. The adenosine phosphates are in the form of 
AMP when its value aproaches 0 and the system is not filled. The EC index is below 1 in the neocyst homogenate.

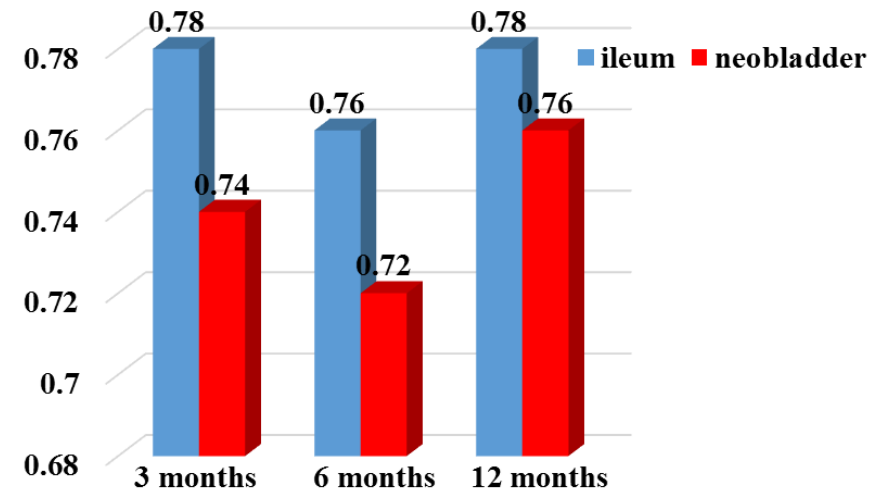

Fig. 2. Energy charge in ileum and neobladder $(\mathrm{p} \leq 0.001)$

Energy potential (EP) is an indicator characterizing the rate of respiration of mitochondria. It is reduced by $23 \%(\mathrm{p} \leq 0.001)$ after 3 months in an artificial bladder compared to ileum. There is a slight increase in this indicator at control of 6 and 12 months, which may indicate a prospect for improving energy production. Data on the dynamics of changes in the EP are presented in Fig. 3.

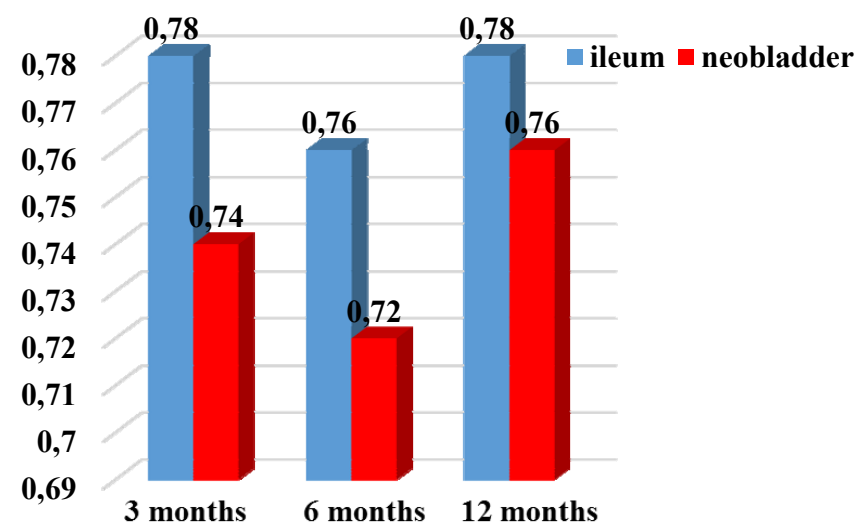

Fig. 3. Energy potential in ileum and neobladder $(\mathrm{p} \leq 0.001)$

The data of phosphorylation index in control studies are statistically reduced by $23.9 \%$ $(\mathrm{p} \leq 0.001)$ in 3 months in neocyst after ileocystoplasty, which testifies to the suppression of energy exchange processes. There is also a slight positive dynamics at the 12 th month of the experiment. The data are provided in Fig. 4.

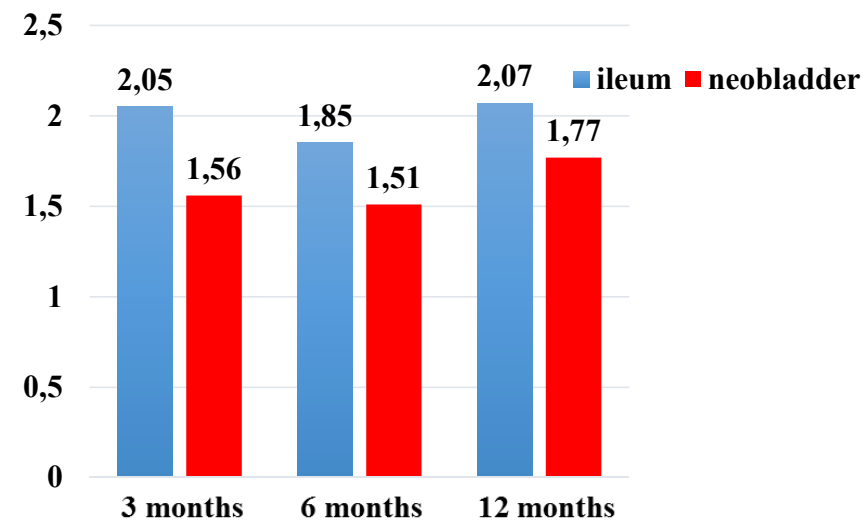

Fig. 4. The index of phosphorylation in ileum and neobladder $(\mathrm{p} \leq 0.001)$ 


\section{Discussion}

The results of the studies performed by different authors indicate high respiratory activity of the intestinal mucosa of experimental animals, which corresponds to the intestine as a highly aerobic organ with a high intensity of energy exchange [17, 18].

There is an imbalance in the ATP-ADP-AMP system in the tissue of the transplant in different periods of postoperative observation. Changes in the level of ATP, which are characterized the development of tissue ischemia, obviously associated with an increase of macroergs in the consumption or a violation of its resynthesis in the course of creatine kinase reaction, glycolysis processes in the respiratory chain of the intestinal mucosa used as a transplant.

External irradiation also causes disturbances in energy metabolism, which can also serve as one of the causes of structural and functional damage of the small intestine [19,20]. The values of the sum of adenosine nucleotides, the energy potential indicative of the respiration rate of mitochondria and the phosphorylation index in the transplant tissue are reduced at different times of observation according to control.

The revealed changes in the level of adenosine nucleotides confirm the severity of the disturbances of the energy homeostasis in the transplant tissue at all stages of the observation. There was also a trend towards an increase in the level of these indicators in the distant postoperative period from 3 months to 12 months of follow-up, which were still well below control. It can be explained by specific conditions of the functioning of the transplant as a bladder and the need to evaluate exogenous and endogenous factors of influence. Thus, a decrease in the level of the studied parameters was noted in the tissue of the transplant from the small intestine at different periods of observation compared with intestinal tissue.

It is still remains an issue the state of the endocrine function of the gut-transplant site and to how it manifests in the initial and in the remote observation periods. Additional clinical and functional studies can help to answer the question in what value the transplant regenerates the function of the neobladder; the degree to which the muscle tonus of its walls changes and whether the blood supply and innervation of the transplant tissue is restored to the proper degree.

\section{Conclusions}

1. Imbalance in the ATP-ADP-AMP system is observed in the tissue of the transplant at different periods of postoperative observation.

2. The indices of adenyl nucleotides were reduced by $36.07 \%$, the energy potential by $23 \%$, in the tissue of the transplant, and three months after the performance of enterocystoplasty.

3 . It is necessary to investigate for further study the connection and influence of energy homeostasis and structural changes in the mucous ileum after the formation of the formal bladder.

\section{References}

[1] Hautmann, R. E., Schumacher, M., Gschwend, J. E., Studer, U. E., Volkmer, B. G. (2006). Long-term results of standard procedures in urology: the ileal neobladder. World Journal of Urology, 24, 305-14. doi: 10.1007/s00345-006-0077-z

[2] Tan, W. S., Lamb, B. W., Kelly, J. D. (2016). Evolution of the neobladder: A critical review of open and intracorporeal neobladder reconstruction techniques. Scandinavian Journal of Urology, 50 (2), 95-103. doi: 10.3109/21681805.2016.1141318

[3] Vasdev, N., Moon, A., Thorpe, A. (2013). Metabolic complications of urinary intestinal diversion. Indian Journal of Urology, 29 (4), 310-315. doi: 10.4103/0970-1591.120112

[4] Monteiro, L. L., Kassouf, W. (2017). Radical Cystectomy is the best choice for most patients with muscle-invasive bladder cancer? Opinion: Yes. International Brazilian Journal Of Urology, 43 (2), 184-187. doi: 10.1590/s1677-5538.ibju.2017.02.03

[5] Liedberg, F., Ahlgren, G., Baseckas, G., Gudjonsson, S., Hakansson, U., Lindquist, S. et. al. (2016). Long-term functional outcomes after radical cystectomy with ileal bladder substitute: does the definition of continence matter? Scandinavian Journal of Urology, 51 (1), 44-49. doi: 10.1080/21681805. 2016.1249943 
[6] Dahl, D. M., McDougal, W. S. (2012).Use of intestinal segments in urinary diversion. Campbell-Walsh urology. Philadelphia: Saunders-Elsevier, 2534-2578. doi: 10.1016/b978-1-4160-69119.00085-2

[7] Stein, R., Rubenwolf, P. (2014). Metabolic Consequences after Urinary Diversion. Frontiers in Pediatrics, 2, 15. doi: 10.3389/fped.2014.00015

[8] Khalil, el-S. A. (2010). Long term complications following ileal conduit urinary diversion after radical cystectomy. Journal of the Egyptian National Cancer Institute, 22 (1), 13-18.

[9] Lee, Y. S., Jung, H. B., Choi, D. K., Cho, S. T., Kim, K. K., Lee, Y. G. (2016). Functional Assessment of the Hautmann Ileal Neobladder with Chimney Modification Using Uroflowmetry and a Questionnaire. BioMed Research International, 2016, 1-6. doi: 10.1155/2016/8209589

[10] Contreras, E. (1990). Adenosine: physiological and pharmacological actions. Archivos De Biologia Y Medicina Experimentales, 23 (1), 1-12.

[11] Ekelund, K. M., Ekblad, E. (1999). Structural, neuronal, and functional adaptive changes in atrophic rat ileum. Gut, 45 (2), 236-245. doi: 10.1136/gut.45.2.236

[12] Knight, G. E., Bodin, P., De Groat, W. C., Burnstock, G. (2002). ATP is released from guinea pig ureter epithelium on distension. American Journal of Physiology-Renal Physiology, 282 (2), 281-288. doi: 10.1152/ajprenal.00293.2000

[13] Ipata, P. L. (2011). Mechanism of ATP loss in nonoxidative contracting muscle. Advances in Physiology Education, 35 (1), 92-94. doi: 10.1152/advan.00102.2010

[14] Zapadniuk, Y. P., Zapadniuk, V. Y., Zakharyia, E. A., Zapadyiuk, B. V. (1983). Laboratornye zhivotnye. Kyiv, 383.

[15] Javorek, D., Gruber, W. et. al.; Bergmeyer, H. U. (Ed.) (1970). Adenosin-5'-triphosphat. Bestimmung mit 3-phosphoglycerat-Kinase. In: Methoden der enzymatischen Analyze. Berlin: Akademie-Verlag, 2019-2024.

[16] Metsler, D. (1980). Biokhimiia. Khimicheskie reaktsii v zhivoi kletke. Vol. 1. Moscow: MIR, 408.

[17] Ahmed, N. et. al. (2006). Biologi of Disease. Garland Science, 600.

[18] Yang, H., Wang, X., Xiong, X., Yin, Y. (2016). Energy metabolism in intestinal epithelial cells during maturation along the crypt-villus axis. Scientific Reports, 6 (1). doi: 10.1038/srep31917

[19] Jaskova, N. S. (2007). Changes of energy metabolism in small intestine on the tenth day after gamma irradiation. Problems of health and ecology, 4 (14), 141-145.

[20] Van Der Schoor, S. R. D., Van Goudoever, J. B., Stoll, B., Henry, J. F., Rosenberger, J. R., Burrin, D. G., Reeds, P. J. (2001). The pattern of intestinal substrate oxidation is altered by protein restriction in pigs. Gastroenterology, 121 (5), 1167-1175. doi: 10.1053/gast.2001.29334 